Distribution Category:

Environmental Sciences (UC-402)

ARM-93-001

\title{
Site Scientific Mission Plan \\ for the \\ Southern Great Plains CART Site
}

\section{July-December 1993}

August 1993

Jeanne M. Schneider and Peter J. Lamb

Cooperative Institute for Mesoscale Meteorological Studies

The University of Oklahoma

Norman, Oklahoma 73019

and

Douglas L. Sisterson

Environmental Research Division

Argonne National Laboratory

Argonne, Illinois 60439

Work supported by United States Department of Energy,

Office of Energy Research,

Office of Health and Environmental Research

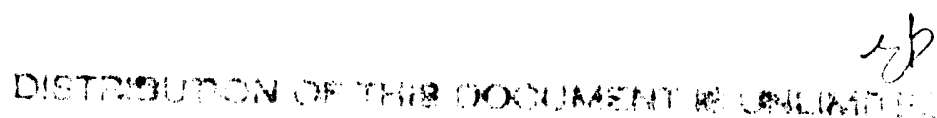




\section{CONTENTS}

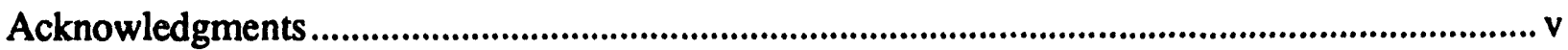

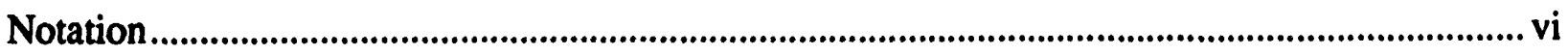

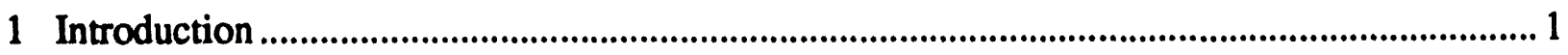

2 Priorities for Site Activities..................................................................................................... 2

3 Summary of Scientific Goals ................................................................................................... 3

4 Establishment of Routine Operations ...............................................................................................

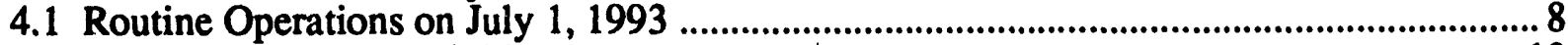

4.2 Site Development Activities ............................................................................................... 13

4.3 Routine Operations by December 31, 1993 .................................................................... 21

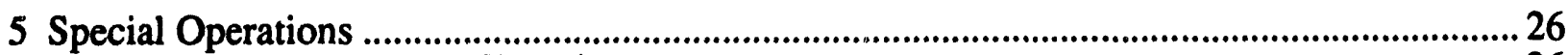

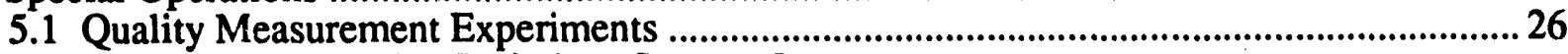

5.2 Intensive Observation Periods to Support Instrument

Development Programs .......................................................................................................... 31

5.3 Intensive Observation Periods to Supplement

5.4 Campaign Planning ........................................................................................................ 32

6 Looking Ahead .............................................................................................................................. 34

\section{FIGURES}

1 Site Development Activities to Establish Routine Operations ...................................................... 15

2 Site Development Activities to Install Central Facility .................................................................... 16

\section{TABLES}

1 Instruments and Observational Systems in Place at the Central, Boundary, and Auxilliary Facilities on July 1, 1993

2 Instruments and Observational Systems in Place at the Extended Facilities on July 1, 1993

3 CART Observation and Measurement Status on June 2, 1993 


\section{TABLES (Cont.)}

4 Timetable for Instrument Deployment and Development of Data Intake Modules

5 Observational Instruments and Systems in Place at Central and Boundary Facilities by December 31, 1993

6 Observation Instruments and Systems in Place at Extended Facilities by December 31, 1993 19

7 Status of CART Observations and Measurements on December 31, 1993 ................................. 21

8 Intensive Observation Periods ................................................................................................... 27

9 Collaborative Campaigns and Activities under Discussion .......................................................33 


\section{ACKNOWLEDGMENTS}

This research was supported by the Atmospheric Radiation Measurement Program of the Atmospheric and Climate Research Division, Office of Health and Environmental Research, Office of Energy Research, U.S. Department of Energy, under contract PNL 144880-A-Q1 at the Cooperative Institute for Mesoscale Meteorological Studies, The University of Oklahoma (Schneider and Lamb), and under contract W-31-109-Eng-38 at Argonne National Laboratory (Sisterson). 


\section{NOTATION}

$\begin{array}{ll}\text { AERI } & \text { atmospherically emitted radiation interferometer } \\ \text { ARM } & \text { Atmospheric Radiation Measurement } \\ \text { AVHRR } & \text { Advanced Very High Resolution Radiometer } \\ \text { BBSS } & \text { balloon-borme sounding system } \\ \text { CART } & \text { Cloud and Radiation Testbed } \\ \text { CCN } & \text { cloud condensation nuclei } \\ \text { CST } & \text { Central Standard Time } \\ \text { CSU } & \text { ColoradJ State University } \\ \text { CU } & \text { Colorado University } \\ \text { DA } & \text { data assimilation } \\ \text { DOA } & \text { Department of Agriculture } \\ \text { EBBR } & \text { energy balance Bowen ratio } \\ \text { EC } & \text { eddy correlation } \\ \text { EOP } & \text { experiment operations plan } \\ \text { EST } & \text { Experiment Support Team } \\ \text { FDDA } & \text { four-dimensional data assimilation } \\ \text { FSL } & \text { Forecast Systems Laboratory } \\ \text { GCIP } & \text { GEWEX Continental-Scale International Project } \\ \text { GCSS } & \text { GEWEX Cloud System Study } \\ \text { GEWEX } & \text { Global Energy and Water Cycle Experiment } \\ \text { GIST } & \text { GEWEX Integrated System Test } \\ \text { GMS } & \text { general measurement strategies } \\ \text { GPS } & \text { global positioning system } \\ \text { GSFC } & \text { Goddard Space Flight Center } \\ \text { GVaP } & \text { GEWEX Water Vapor Project } \\ \text { HD } & \text { hierarchical diagnosis } \\ \text { IDP } & \text { Instrument Development Program } \\ \text { IOP } & \text { Intensive Observation Period } \\ \text { ISLSCP } & \text { International Satellite Land-Surface Climatology Project } \\ \text { IRF } & \text { instantaneous radiative flux } \\ \text { ISS } & \text { integrated sounding system } \\ \text { LBLRTM } & \text { line-by-line radiative transfer model } \\ \text { MAPS } & \text { Mesoscale Analysis and Prediction System } \\ \text { MFRSR } & \text { multifilter rotating shadowband radiometer } \\ \text { MWR } & \text { microwave radiometer } \\ \text { NCAR } & \text { National Center for Atmospheric Research } \\ \text { NGM } & \text { Nested Grid Model } \\ \text { NIP } & \text { normal-incidence pyrheliometer } \\ \text { NIST } & \text { National Institute of Standards and Technology } \\ \text { NMC } & \text { National Meteorological Center } \\ \text { NOAA } & \text { National Oceanic and Atmospheric Administration } \\ \text { NSSL } & \text { National Severe Storms Laboratory } \\ \text { NWS } & \text { National Weather Service } \\ & \end{array}$




\section{NOTATION (Cont.)}

QME

RASS

SCM

SGP

SIROS

SMOS

SST

UAV

UV

WPL quality measurement experiment

radio acoustic sounding system

single-column model

southern Great Plains

solar and infrared radiation observing station

surface meteorological observation station

Site Scientist Team

unmanned aerospace vehicle

ultraviolet

Wave Propagation Laboratory 
viii
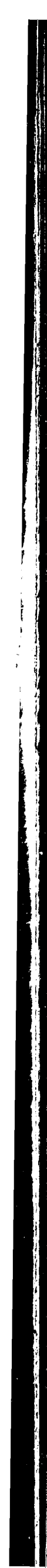


\section{SITE SCIENTIFIC MISSION PLAN \\ FOR THE SOUTHERN GREAT PLAINS CART SITE}

\section{INTRODUCTION}

The southern Great Plains (SGP) Cloud and Radiation Testbed (CART) site is designed to help satisfy the data needs of the Atmospheric Radiation Measurement (ARM) Program Science Team. This document defines the scientific priorities for site activities during the six months beginning on July 1, 1993, and also looks forward in lesser detail to subsequent sixmonth periods. The primary purpose of this Site Scientific Mission Plan is to provide guidance for the development of plans for site operations. It also provides a planning focus for the ARM Functional Teams (Management Team, Experiment Support Team, Operations Team, Data Management Team, Instrument Team, and Campaign Team), and it serves to disseminate the current plans more generally within the ARM Program and among the Science Team. This document includes a description of the site's operational status and the primary envisaged site activities, together with information concerning approved and proposed Intensive Observation Periods. Amendments will be prepared and distributed whenever the content changes by more than $30 \%$ within a six-month period. The primary users of this document are the site operator, the site scientist, the Science Team through the ARM Program Science Director, the ARM Program Experiment Center, and the aforementioned ARM Program Functional Teams. This plan is a living document that will be updated and reissued every six months as the observational facilities are developed, tested, and augmented and as priorities are adjusted in response to developments in scientific planning and understanding. 


\section{PRIORITIES FOR SITE ACTIVITIES}

In descending order, we rank the priorities of site activities for July-December 1993 as follows:

1. Establish routine operations.

2. Implement quality measurement experiments. ${ }^{*}$

3. Support the Instrument Development Program.

4. Plan and implement Intensive Observation Periods.

5. Plan campaigns.

Within this ranking, the first activity is by far the most important, with the second and third of moderate importance and the last two of lesser importance during this six-month period. This ranking reflects both our scientific assessment and the maturity of the ARM Program and the SGP CART site. Methodologies for developing scientifically sound and cost-effective plans for Intensive Observation Periods (IOPs) and campaigns are still under development, a fact that is reflected in the relative lack of detail in the IOP and campaign portions of this edition of the Site Scientific Mission Plan (Sections 5.3-5.5). However, the ARM CART Program and the SGP site are both maturing rapidly, and our priorities for site activities will shift accordingly, a subject that will be addressed in Section 6.

Simply stated, the primary scientific goal for this six-month period is the translation of site implementation activities into credible data streams for as many parameters as possible. Establishment of routine operations requires the continuing development of observational, data intake, display, and dissemination capabilities, as well as an intense effort on the part of the instrument mentors, the Site Scientist Team (SST), and the Experiment Center to determine the data quality. Even so, there will be opportunities to address several scientific subobjectives, which will be summarized in Section 3.

\footnotetext{
${ }^{\star}$ A quality measurement experiment (QME) compares multiple data streams against expectations about the outcome of the comparison (the hypothesis of the experiment) and may or may not require special operations (e.g., extra balloon-boume sounding system [BBSS] launches or temporary deployment of a scanning radar). The QMEs are an important component of the ARM data quality assurance effort.
} 


\section{SUMMARY OF SCIENTIFIC GOALS}

The primary goal of the SGP CAR'T site activities is to produce data adequate to support significant research addressing the ARM Program objectives. These overall objectives, as paraphrased from the ARM Program Plan, are the following:

- To describe the radiative energy flux profile of the clear and cloudy atmosphere

- To understand the processes determining the flux profile

- To parameterize the processes determining the flux profile for incorporation into general circulation models

To address these scientific issues, an empirical data set must be developed that includes observations of the evolution of the radiative state of the column of air over the entire $275-\mathrm{km} x$ $325-\mathrm{km}$ SGP CART site, as well as the processes that control that radiative state, in sufficient detail and quality to support the investigations proposed by the ARM Science Team. This data set must include measurements of the radiative fluxes (solar and infrared) and nonradiative fluxes (mass fluxes of significant species; turbulent fluxes of moisture, heat, and momentum) occurring within the column and across its boundaries; the distribution of radiatively significant particulates, aerosols, and gases; the cloud types, composition, and distribution (depth, fractional coverage, and layering); the complete thermodynamic description of the columnar air mass (temperature, pressure, concentrations of all three phases of water); the state and characteristics of the underlying surface (the lower boundary condition); and the processes within the column that create or modify all of these characteristics (including precipitation, evaporation, and generation of condensation nuclei). Basic, continuous observations must be made as often as is feasible within budgetary constraints. For limited time periods, these observations will be supplemented by directed IOPs providing higher resolution or difficult-to-obtain in situ data.

Beyond simply providing the necessary data streams, it is imperative to determine their character and quality as early as possible in the observational program. This evaluation will provide the basic operational understanding of the data necessary for an ongoing program of such scope. Although there will be both reason and ample opportunity to develop a further understanding of the ARM measurements over the course of the program, it is important to investigate and ensure the data quality as soon as possible. In this regard, early and definitive quality measurement experiments (QMEs) will set the standard for the rest of the program and will establish confidence in the measurements. 
The SGP CART site is the first of several global locations chosen and instrumented for data collection. As summarized in a draft report by Sisterson and Barr, the scientific issues to be addressed by using data from a midlatitude continental CART observatory include the following:

- Radiative transfer under conditions of clear sky and general cloudiness

- Scattering and absorption in cloudy atmospheres

- The role of surface physical and vegetative properties in the column energy balance

- Other complications in the radiative balance in the atmosphere, particularly those due to aerosols, cloud condensation nuclei ( $\mathrm{CCN})$, and cloud-aerosol radiative interactions

- Nonradiative flux parameterizations

- Cloud formation, maintenance, and dissipation

- Feedback processes between different phenomena and different domains

The variety, density, and atmospheric volumetric coverage of the SGP instrumentation will be the most comprehensive at any ARM site, and the SGP site will experience a wider variety of atmospheric conditions than any other ARM site. The resulting data will support a greater range and depth of scientific investigation than data from any other location, making it imperative for the ARM Program to develop and maintain a high-quality, continuous data stream from the SGP site.

In the process of distilling the measurements required by the Science Team proposals, the Experiment Support Team (EST) developed a set of general measurement strategies (GMS), which represent groups of experiments requiring measurements with similar characteristics. The initial GMS are designed to quantify the instantaneous radiative flux (IRF) and to support the requirements of the single-column model (SCM)/data assimilation (DA) and hierarchical diagnosis (HD) research. In 1992, the EST defined a set of critical measurements that has driven much of the SGP site development to date. The EST continues to prioritize instrument deployment scheduling. Because the site implementation is phased, IRF measurements began 
first. They will be followed in the six-month period treated here by the initiation of important measurements designed to support the SCM, DA, and HD experiments.

Despite weather-related construction delays, site development is nearing completion, the site management structure is evolving to meet the changing needs of the site, and the data stream is a steadily growing trickle that should be in full spate by the end of the calendar year. Our ability to meet the long-term observational needs of the Science Team will depend on continued instrument development and deployment (especially at the boundary and auxiliary facilities), as well as careful orchestration of IOPs and collaborative campaigns during the next two years. The planned instrument acquisitions and installations must be completed (especially the optical, aerosol, and calibration instrumentation), while our Instrument Development Program (IDP) research continues to push for the best means to automatically profile water vapor (day-capable Raman lidar or global positioning system analysis) and to define the clouds (better ceilometers, supportable whole-sky imaging, scanning radars or lidars).

The late summer, fall, and early winter at the SGP site typically include a wide range of conditions -- from high humidity, heat, and haze; through organized convective activity producing significant precipitation events with associated stratocumulus decks; to fair, cool weather with cirrus. In response to the GMS workshops and break-out sessions at the March 1993 Science Team meeting, site activities during July-December 1993 will consolidate an interim suite of basic IRF general measurements including limited sky imagery, cloud base observations, and hourly visual observations of sky conditions above the central facility during operator hours. Beginning in August, a second daily BBSS launch will be initiated at the central facility, specifically to coincide with the overpass of one of two polar orbiting satellites as requested by the IRF group. Successful deployment of the atmospherically emitted radiation interferometer (AERI), a laser ceilometer, and an interim whole-sky imaging system, together with continuous operation of the multifilter rotating shadowband radiometers (MFRSRs) and microwave radiometers (MWRs), will also be an important element in the IRF measurements.

During this six-month period, we will also begin to address SCM, DA, and HD measurement needs with a more complete continuous data stream that includes radar profiling from the central facility: surface data collection from most of the extended facilities; and measurement of temperature, humidity, and wind profiles from the boundary facilities. Seasonal IOPs have been proposed to support the SCM research, but with the many-month lead time necessary to schedule research aircraft, it is important that we immediately begin design of one or more consolidated, all-GMS aircraft-supported IOPs to obtain needed in situ data. 
Dissemination of the results from the June National Center for Atmospheric Research (NCAR) IOP and a fall SCM IOP will provide the first opportunities within the ARM Program to test and tune both Science Team single-column and data assimilation models, as well as external data sources such as the National Meteorological Center's (NMC's) Mesoscale Analysis and Prediction System (MAPS) analyses. Both of these IOPs will involve frequent, simultaneous rawinsonde launches from at least four locations within the SGP site for ten-day to two-week periods, with supporting surface data.

In summary, our goal for this six-month period is to begin providing the Science Team with a suite of measurements that will support initiation of its research, while establishing solid instrument calibration and maintenance procedures and continuing the series of QMEs. The importance of the data quality assurance effort is paramount and central to the success of the entire program. 


\section{ESTABLISHMENT OF ROUTINE OPERATIONS}

The ARM Program Plan repeatedly asserts that the comparison of model results with observations must occur on a continuing, real-time basis throughout the experiment. This is the primary rationale for the establishment of decade-long routine operations at the SGP CART site. The validity of this strategy is confirmed in the experimental designs of the Science Team members. The overwhelming majority of the highest priority measurements in the extant experimental designs are based on regular (i.e., routine) observations. Continuous observations are also specified in the ARM Program Plan because of their utility in offsetting the lack of complete geographic coverage of the CART sites. Implicit in the philosophy of choosing just a few observational locations was the understanding that long time series of data could sample enough of the natural variability to constitute a useful surrogate for spatial statistics, both within and beyond the bounds of the CART sites. The heart of any statistical study is an uninterrupted sequence of high-quality observations; hence, developing and maintaining a robust observational facility as soon as possible is crucial.

Scientifically and logistically, routine operations will serve as the basis and background for all nonroutine operations, including QMEs, instrument development activities, IOPs, and collaborative campaigns directed toward obtaining difficult-to-gather or expensive in situ data. Consequently, development and validation of the basic observations must take top priority during the first 18 months of occupation of the site, and care needs to be taken not to dilute these efforts in a rush to support special operations. Our opinion is that the establishment of routine operations and the execution of QMEs therefore far outweigh all other activities during the next six months and should receive a corresponding share of programmatic effort and fiscal support.

The SST will play a role in the establishment of routine operations, providing guidance to the site operations manager and his staff on scientific matters related to the data stream, answering questions about active instrument problems, reviewing instrument maintenance and calibration schedules and procedures, reviewing designs for infrastructure supporting new instruments, contributing to the design of the standard operating procedure, helping to establish forecast support for routine operations, and advising the Experiment Center when an instrument's operating environment is suboptimal. The SST will generally oversee the quality control effort at the CART site, a continuous activity that includes daily monitoring of the CART data streams in collaboration with the staff at the central facility. 
During this six-month period, our first priority will be to compare similar data streams from different instrument packages, a natural and obvious sequel to the efforts of the instrument mentors. A number of QMEs will be developed and conducted by employing routine observations. Examples include (1) intercomparison of the observed and calculated broadband radiative surface fluxes; (2) virtual temperature and velocity profiles from the BBSS and the 915- and 50-MHz profilers; (3) temperature, humidity, and pressure measurements from the surface meteorological observation station (SMOS), the 60-m tower, and the energy balance Bowen ratio (EBBR) system; and (4) momentum, heat, and moisture fluxes derived from the EBBR and eddy correlation (EC) systems. These studies will refine or validate the vendorspecified operating ranges, precision, and accuracy of the CART instruments. A more subtle task will be the comparison of observations of different parameters to determine if they make physical sense in the context of changing conditions. This work will be inspired by the daily monitoring of the data stream and the QMEs already mentioned. Once the first round of QMEs is well underway, the efforts of the SST will shift to dissemination of the QME results, to new instruments and more difficult QMEs that require special observations or longer time series, and (in a broader sense) to the planning and implementation of IOPs.

\subsection{Routine Operations on July 1, 1993}

\subsubsection{Instruments and Observational Systems}

The fruit of the previous 16 months of site development is most evident at the central facility, which is nearing the end of its primary development. The creation of the extended facilities is well underway, and preliminary work for the boundary facilities has begun. The auxiliary facil.. ies, which are intended to be the base for the three-dimensional observations of the cloud field over the central facility, will not be developed until plans for whole-sky imaging and scanning cloud radar or lidar are more mature. The systems and instruments in place are summarized in Tables 1 and 2.

\subsubsection{Launch Schedule for BBSS}

Until the full suite of remote-sensing systems is deployed to perform deep, detailed wind, temperature, and moisture soundings of the troposphere under a wide range of conditions, the BBSS will continue to be an expensive workhorse because of the cost of expendables associated with an ambitious rawinsonde launch schedule. The number of BBSS launches sitewide should eventually be reduced to a minimum needed to support routine cross checks on the remotely 
TABLE 1 Instruments and Observational Systems in Place at the Central, Boundary, and Auxiliary Facilities on July 1, 1993

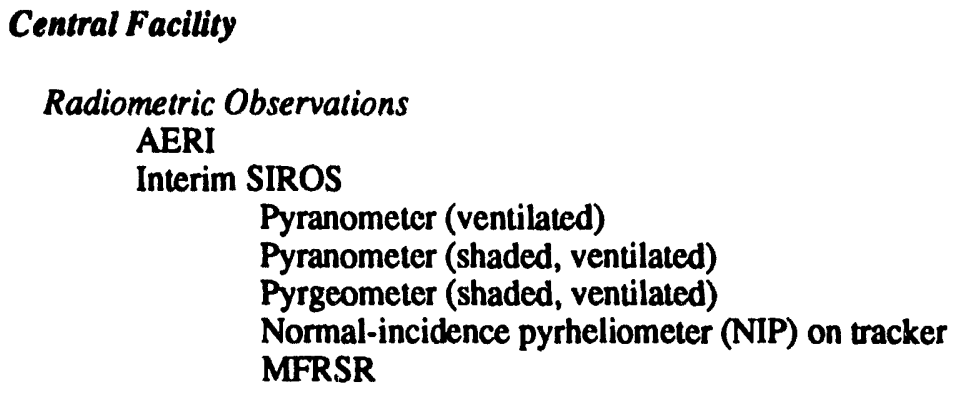

Wind, Temperature, and Humidity Sounding Systems

BBSS

915-MHz profiler with RASS (radio acoustic sounding system)

MWR

Others

SMOS

EBBR

Temperature and humidity probes at $60 \mathrm{~m}$ on tower

Boundary Facilities

In preparation at Hillsboro, Kansas; Vici, Oklahoma; and Morris, Oklahoma.

Auxiliary Facilities

None in preparation.

sensed measurements, but we are a number of years from that goal. At the start of this period, because of budgetary constraints and the continuing site development activities, the launches will continue once per weekday at 1500 Central Standard Time (CST). (Launch time is $30 \mathrm{~min}$ earlier; the stated time represents the approximate midpoint of the flight.) This launch time was originally chosen both to characterize the deepest boundary layer and to coordinate approximately with afternoon satellite overpasses. The frequency of launches will be increased during this six-month period, as discussed in Section 4.2.

\subsubsection{Observations}

The observations being delivered to the Experiment Center from the SGP CART site as of June 2, 1993, are summarized in Table 3. Platforms listed as "NOT available" are undergoing modification (the EBBR) or will be replaced soon (the interim solar and infrared observation station [SIROS]). The other instruments operating on the site that are not on this list (the SMOS, 
TABLE 2 Instruments and Observational Systems in Place at the Extended Facilities on July 1, 1993a

\begin{tabular}{|c|c|c|c|c|c|c|}
\hline Location & SMOS & SIROS & EBBR & $\mathrm{EC}$ & MFRSR & Data Intake \\
\hline \multicolumn{7}{|l|}{ Kansas } \\
\hline $\begin{array}{l}\text { Ashton } \\
\text { Coldwater } \\
\text { Plevna } \\
\text { Elk Falls (Howard) } \\
\text { Tyro } \\
\text { Towanda } \\
\text { Lamed (Burdett) } \\
\text { LeRoy } \\
\text { Heston (Halstead) } \\
\text { Hillsboro }\end{array}$ & $\begin{array}{l}\mathbf{X} \\
\mathbf{X} \\
* \\
\mathbf{X} \\
\vdots \\
* \\
* \\
* \\
* \\
-\end{array}$ & $\begin{array}{l}* \\
* \\
* \\
* \\
* \\
* \\
* \\
* \\
*\end{array}$ & $\begin{array}{l}\mathbf{X} \\
\mathbf{X} \\
\mathbf{X} \\
* \\
- \\
- \\
- \\
- \\
\end{array}$ & $\begin{array}{l}- \\
- \\
- \\
* \\
* \\
* \\
* \\
* \\
-\end{array}$ & $\begin{array}{l}* \\
* \\
* \\
* \\
* \\
* \\
* \\
* \\
*\end{array}$ & $\begin{array}{c}\text { Modem } \\
\text { Modem } \\
\text { Diskette } \\
\text { Diskette } \\
* \\
* \\
* \\
* \\
* \\
*\end{array}$ \\
\hline \multicolumn{7}{|l|}{ Oklahoma } \\
\hline $\begin{array}{l}\text { Ringwood } \\
\text { Okmulgee } \\
\text { Meeker } \\
\text { Cordell } \\
\text { El Reno } \\
\text { Pawhuska } \\
\text { Vici } \\
\text { Morris } \\
\text { Ft. Cobb } \\
\text { Cyril } \\
\text { Byron }\end{array}$ & $\begin{array}{l}\mathbf{X} \\
* \\
\mathbf{X} \\
- \\
- \\
- \\
- \\
- \\
- \\
* \\
*\end{array}$ & $\begin{array}{l}* \\
* \\
* \\
* \\
* \\
* \\
* \\
* \\
* \\
* \\
*\end{array}$ & $\begin{array}{l}\mathbf{X} \\
- \\
\mathbf{X} \\
\mathbf{X} \\
* \\
* \\
- \\
* \\
- \\
- \\
-\end{array}$ & $\begin{array}{l}- \\
* \\
- \\
- \\
- \\
\dot{-} \\
\dot{*} \\
* \\
*\end{array}$ & $\begin{array}{l}* \\
* \\
* \\
* \\
* \\
* \\
* \\
* \\
* \\
* \\
*\end{array}$ & $\begin{array}{c}\text { Modem } \\
* \\
\text { Modem } \\
\text { Diskette } \\
* \\
* \\
* \\
* \\
* \\
* \\
*\end{array}$ \\
\hline
\end{tabular}

a $\mathrm{X}$ means installed, * means planned for installation, - means no installation currently planned, "diskette" means data are retrieved manually on diskette, "modem" means data are retrieved remotely by telephone. All sites will eventually transfer data by modem to the central facility. Eight of the sites are co-located with either an Oklahoma Mesonet or an NWS site, so that a SMOS would be relatively redundant and is not planned. Each site will have either an EBBR (over pasture) or an EC (over cropland) system. Two sites have not yet been assigned a location and are not listed. 
TABLE 3 CART Observation and Measurement Status on June 2, 1993

\begin{tabular}{lll}
\hline Observation & Platform & Comments \\
\hline
\end{tabular}

\section{From the BBSS}

Sonde temperature profile

Sonde relative humidity profile

Sonde pressure profile

Sonde wind speed profile

Sonde wind direction profile

\section{From the MWR}

Column-integrated precipitated water vapor

Column-integrated liquid water path

23.8-GHz brightness temperature

31.4-GHz brightness temperature

Infrared (9.5-11.5 $\mu \mathrm{m})$ sky temperature

\section{From the interim SIROS}

Direct beam-normal solar irradiance

Downwelling hemispheric solar irradiance

Downwelling hemispheric diffuse solar irradiance

Downwelling hemispheric infrared irradiance

From the AERI

Wave number $\left(520-1800 \mathrm{~cm}^{-1}\right)$

Mean infrared radiance spectra ensemble

Standard deviation of spectra ensemble

Wave number $\left(1800-2725 \mathrm{~cm}^{-1}\right)$

Mean infrared radiance spectra ensemble

Standard deviation of spectra ensemble

Mean radiance at 675-680, 700-705, 985-990, $2295-2300,2282-2287,2510-2515 \mathrm{~cm}^{-1}$

Standard deviation of the radiance at 675-680, 700-705,985-990, 2295-2300, 2282-2287, $2510-2515 \mathrm{~cm}^{-1}$

Brightness temperature at 675-680, 700-705, 985-990, 2295-2300, 2282-2287, $2510-2515 \mathrm{~cm}^{-1}$ sgpsonde1

sgpsonde1

sgpsonde1

sgpsonde1

sgpsonde1

sgpwvrlos 1

sgpwurlos 1

sgpwvrlos 1

sgpwvrlos 1

sgpwvrlos 1

sgpbsrn 1.a1

sgpbsrnl.al

sgpbsm 1.a1

sgpbsm 1.a1

sgpaerilchl.al

sgpaerilchl.a1

sgpaerilchl.al

sgpaerilch2.a1

sgpaerilch2.a1

sgpaeri1ch2.al

sgpaeril summary.al

sgpacri 1 summary.a1

sgpaeri l summary.al
Available

Available

Available

Available

Available

Available

Available

Available

Available

NOT available

NOT available

NOT available

NOT available

NOT available

Available for IOP Available for IOP Available for IOP Available for IOP Available for IOP Available for IOP Available for IOP

Available for IOP

Available for IOP 
TABLE 3 (Cont.)

$\begin{array}{lll}\text { Observation } & \text { Platform } & \text { Comments }\end{array}$

From the EBBR

Sensible heat flux to surface

Latent heat flux to surface

Net radiation flux to surface

Soil heat flux to surface

From the interim SIROS

Direct beam-normal solar irradiance

Calculated downward hemispherical diffuse solar irradiance

Downwelling hemispherical solar irradiance

Solar zenith angle used in calculation

From the MWR

Average (5-min) column-integrated water vapor Average (5-min) column-integrated liquid water Average (5-min) blackbody equivalent brightness temperature

Water vapor density profile

From the MFRSR

Optical depth $(415,500,610$ $665,862,940 \mathrm{~nm})$

Solar constant (same frequency as above)

Optical depth root mean square error (same frequency as above) sgp30ebbr.a1

sgp30ebbr.a1

sgp30ebbr.a1

sgp30ebbr.al

sgpbsm lcalc.a1

sgpbsrn1calc.a1

sgpbsrn 1calc.a1

sgpbsm1calc.a1

sgpmwrlavg.cl

sgpmwrlavg.c1

sgpmwrlavg.c1

sgpmwrlprof.cl

NOT available

NOT available

NOT available

NOT available

From gridded three-dimensional (3-D) and two-dimensional (2-D) fields surrounding the SGP CART site, based on the smoothed NGM data product

Temperature (3-D)

Relative humidity (3-D)

Horizontal wind components (3-D)

Vertical (omega) wind component (3-D)

Geopotential heights (3-D)

Surface and tropospheric pressure (2-D)

12-hr precipitation (2-D)

$\begin{array}{ll}\text { ngm250.c1 } & \text { Available } \\ \text { ngm250.c1 } & \text { Available } \\ \text { ngm250.c1 } & \text { Available } \\ \text { ngm250.c1 } & \text { Available } \\ \text { ngm250.c1 } & \text { Available } \\ \text { ngm250.c1 } & \text { Available } \\ \text { ngm250.c1 } & \text { Available }\end{array}$

Horizontally averaged values of three fields at the SGP CART site, based on data from ngm250.cI

Surface pressure (reduced to sea level)

Tropopause pressure

Tropopause temperature ngm250derived

ngm250derived

ngm250derived
Available

Available

Available

Available

Available

Available

Available

NOT available

NOT availlable

$\begin{array}{ll}\text { rsrlangley } & \text { NOT available } \\ \text { rsrlangley } & \text { NOT available }\end{array}$

$\begin{array}{ll}\text { rsrlangley } & \text { NOT available } \\ \text { rsrlangley } & \text { NOT available }\end{array}$ 
TABLE 3 (Cont.)

\begin{tabular}{|c|c|c|}
\hline Observation & Platform & Comments \\
\hline \multicolumn{3}{|c|}{ Slab-averaged vertical profiles of fields at the SGP CART site, based on data from ngm 250} \\
\hline $\begin{array}{l}\text { Temperature }(T) \\
-\left(u^{*} d T / d x+v^{*} d T / d y\right) \\
\text { Water vapor mixing ratio }(q) \\
-\left(u^{*} d g / d x+v^{*} d q / d y\right) \\
\text { Horizontal wind components ( } u \text { and } v) \\
\text { (du/dx }+d v / d y) \\
-\left(u^{*} d u / d x+v^{*} d u / d y\right) \text { and }-\left(u^{*} d v / d x+v^{*} d v / d y\right) \\
\text { Geopotential height }(Z) \\
d Z / d x \text { and } d Z / d y \\
d 2 T / d x 2, d 2 T / d y 2 \\
d 2 q / d x 2, d 2 q / d y 2 \\
d 2 u / d x 2, d 2 u / d y 2, d 2 v / d x 2, d 2 v / d y 2\end{array}$ & $\begin{array}{l}\text { ngm250derived } \\
\text { ngm250derived } \\
\text { ngm250derived } \\
\text { ngm250derived } \\
\text { ngm250derived } \\
\text { ngm250derived } \\
\text { ngm250derived } \\
\text { ngm250derived } \\
\text { ngm250derived } \\
\text { ngm250derived } \\
\text { ngm250derived } \\
\text { ngm250derived }\end{array}$ & $\begin{array}{l}\text { Available } \\
\text { Available } \\
\text { Available } \\
\text { Available } \\
\text { Available } \\
\text { Available } \\
\text { Available } \\
\text { Available } \\
\text { Available } \\
\text { Available } \\
\text { Available } \\
\text { Available }\end{array}$ \\
\hline
\end{tabular}

the $915-\mathrm{MHz}$ profiler, and the temperature and humidity sensors on the $60-\mathrm{m}$ tower) either are still under evaluation by the instrument mentors or are awaiting the creation of the data intake modules necessary to add their data to the SGP data stream.

\subsubsection{Measurements}

The measurements being produced at the Experiment Center as of May 7, 1993, for distribution to the Science Team are listed in Table 3. This summary includes both the measurements derived from the SGP CART site data and the data streams from sources external to ARM (e.g., the gridded data from the National Weather Service's [NWS's] Nested Grid Model [NGM]).

\subsection{Site Development Activities}

\subsubsection{Facilities}

The site data system will be extended to include electronic (via telephone) data transfers from all extended and boundary facility instruments at the SGP CART site, and it should include a broader suite of data display capabilities. The calibration trailer at the central facility will be equipped, and the modifications on the aerosol trailer should be finisheu as well. The major developmental effort will focus on the extended and boundary facilities. The primary 
developmental phase of the site data system should be completed by October. Figure 1 summarizes site development activities. Milestones and complex tasks are distinguished from simple tasks or activities.

\subsubsection{Instruments}

The central facility will see the addition of the complete SIROS, a pyranometer and pyrgometer to measure upwelling radiation at $25 \mathrm{~m}$ on the $60-\mathrm{m}$ tower, the Heimann infrared thermometer, the interim whole-sky imager, the Belfort laser (interim) ceilometer, the $50-\mathrm{MHz}$ profiler with radio acoustic sounding system (RASS), the ultraviolet (UV) spectral radiometer, the EC sensors (both on the tower and near the surface), and some subset of the aerosol instrumentation (at least an integrating nephelometer and an optical absorption system), as indicated in Figure 2. The extended facilities will be equipped as indicated in Table 2. The first three boundary facilities will initially include a BBSS, an MWR, and (at one boundary facility) an AERI, all in close proximity to the National Oceanic and Atmospheric Administration (NOAA) 404-MHz profilers. When these instruments are installed, the first phase of instrumentation at the SGP CART site will be complete.

\subsubsection{Data Intake Modules for the Site Data System}

Several of the installed instruments and all of the new instruments will require creation of software to transfer the data from the instrument platforms to the site data system. The current schedule for data intake module development is summarized in Table 4.

\subsubsection{Measurements}

The Experiment Center will continue to prepare software to produce measurements from the available observations. The status of the measurements near the beginning of this six-month period is summarized in Table 3, and the anticipated list of measurements distributed by the end of the period is in Tables 5 and 6. (Plans for the development of auxiliary facilities are not in place and therefore are not specified in Tables 5 and 6.)

\subsubsection{Limiting Factors}

The costs associated with BBSS launches (including both expendables and manpower) will be a burden on the operations budget until they are replaced by continuous, unmanned 


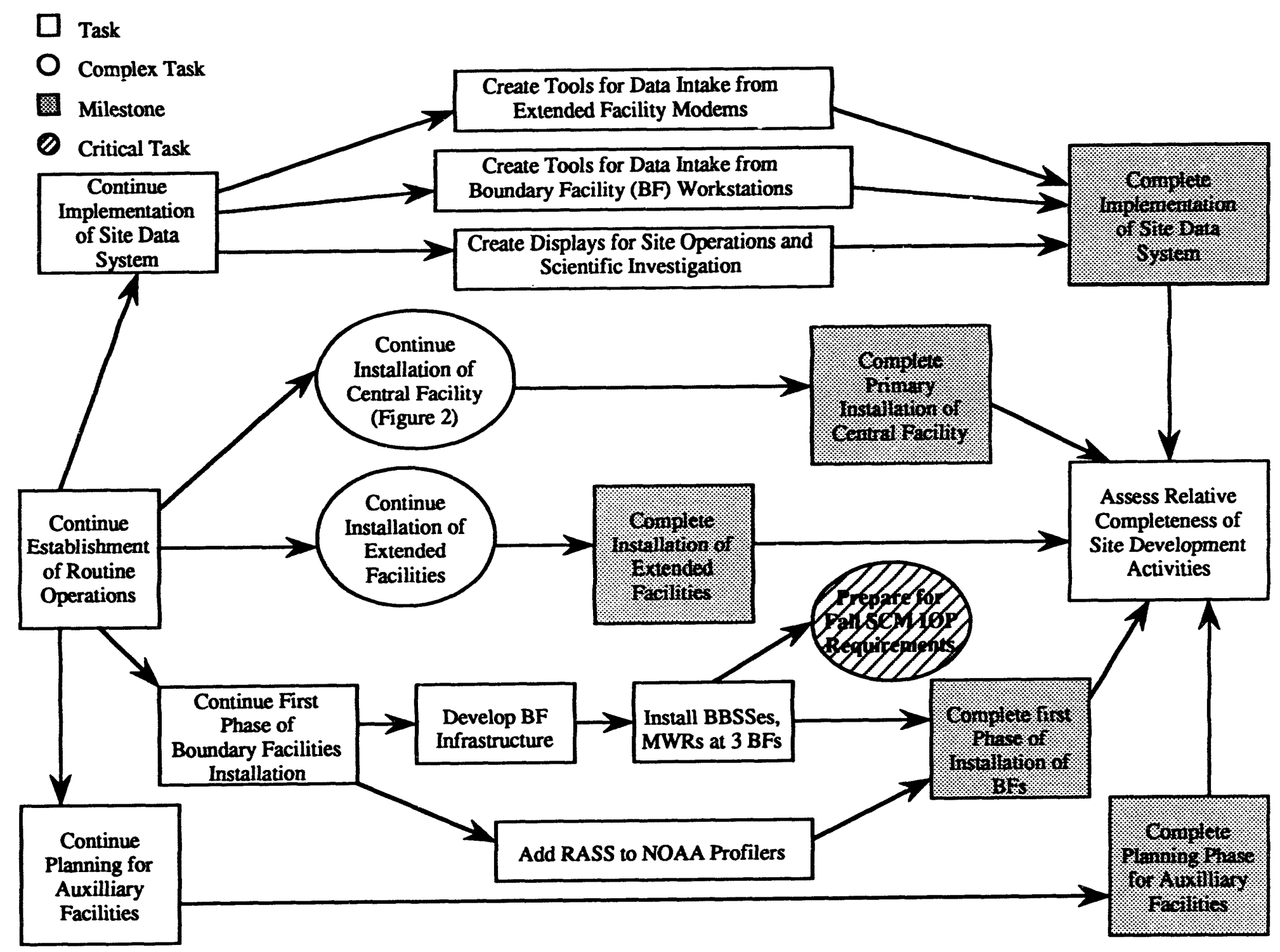

FIGURE 1 Site Development Activities to Establish Routine Operations 


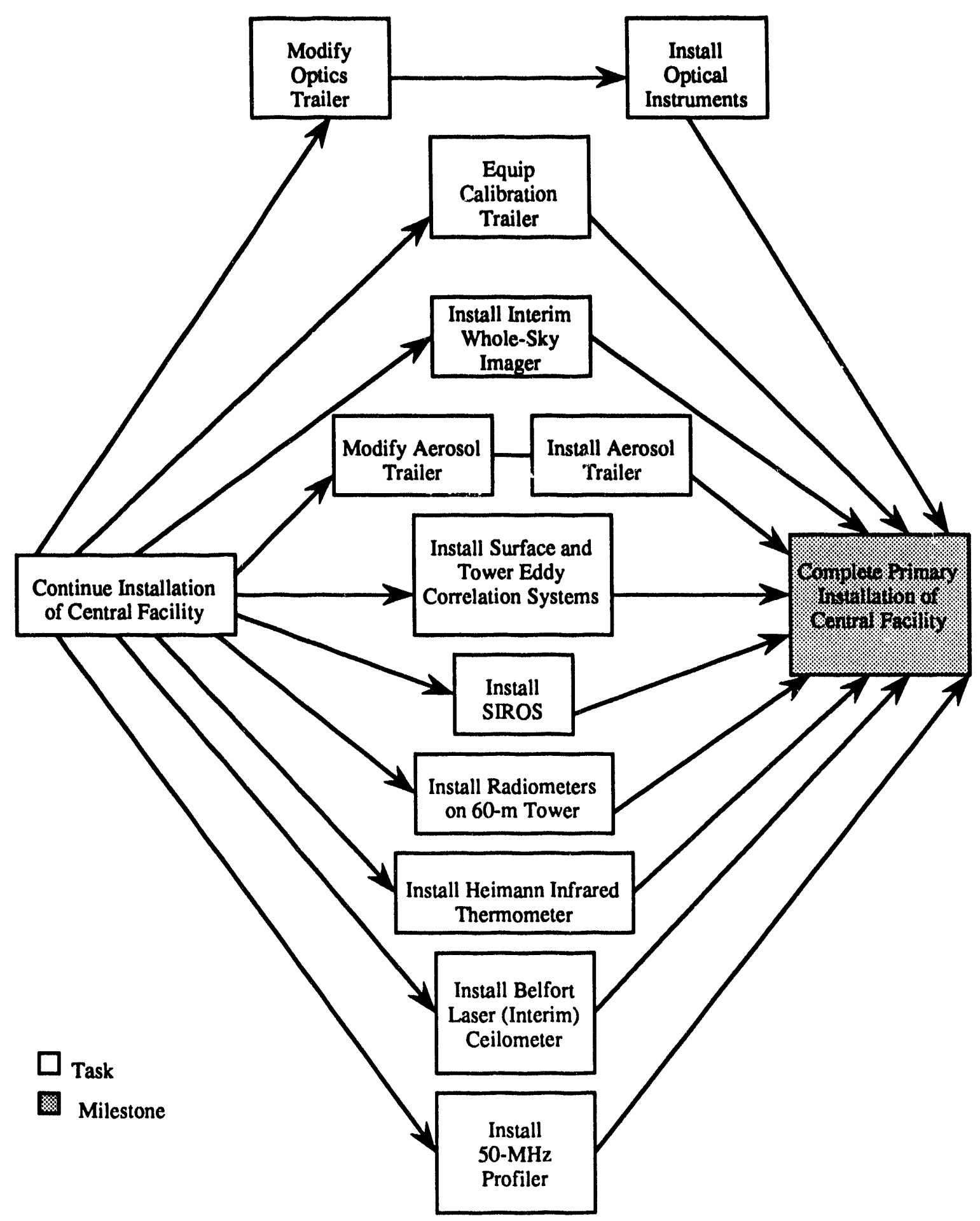

FIGURE 2 Site Development Activities to Irstall Central Facility 
TABLE 4 Timetable for Instrument Deployment and Development of Data Intake Modules

\begin{tabular}{|c|c|c|c|c|}
\hline Instrument & $\begin{array}{c}\text { Date } \\
\text { Availableb }^{\text {b }}\end{array}$ & $\begin{array}{l}\text { Data Intake } \\
\text { Datec }^{c}\end{array}$ & $\begin{array}{l}\text { Time } \\
\text { Required }\end{array}$ & Comments \\
\hline SIROS & August & June & ASAP & $\begin{array}{l}\text { Uses "upgraded" MFRSR data } \\
\text { logger. }\end{array}$ \\
\hline $\begin{array}{l}\text { Radiometers on } \\
60 \text { - } \mathrm{m} \text { tower }\end{array}$ & August & - & $? ?$ & $\begin{array}{l}\text { Will be attached to existing } \\
\text { Campbell data logger. }\end{array}$ \\
\hline $\begin{array}{l}\text { Heimann infrared } \\
\text { thermometer }\end{array}$ & $\begin{array}{l}\text { At PNL; to site } \\
\text { mid August }\end{array}$ & Mid May & ASAP & $\begin{array}{l}\text { Will be a modification of existing } \\
\text { MWR instrument. Rain dew } \\
\text { sensor also being added. }\end{array}$ \\
\hline $\begin{array}{l}\text { Belfort laser } \\
\text { ceilometer }\end{array}$ & At PNL; to site?? & TBD & Fall IOP & - \\
\hline $\begin{array}{l}\text { Interim whole-sky } \\
\text { imager }\end{array}$ & $? ?$ & TBD & Fall IOP & $\begin{array}{l}\text { Initial plan is for limited data } \\
\text { intake of images with no } \\
\text { processing. }\end{array}$ \\
\hline AERI & Now & - & - & $\begin{array}{l}\text { Instrument operation issues must } \\
\text { be resolved. }\end{array}$ \\
\hline $\begin{array}{l}\text { All-weather } \\
\text { absolute } \\
\text { radiometer }\end{array}$ & $? ?$ & TBD & $? ?$ & Uses MFRSR data logger. \\
\hline BBSS & Now & - & - & - \\
\hline SMOS & Now & - & - & - \\
\hline $\begin{array}{l}\text { MWR and BBSS } \\
\text { at boundary } \\
\text { facilities }\end{array}$ & $\begin{array}{l}\text { MWRs mid May; } \\
\text { BBSSes in July }\end{array}$ & $? ?$ & Fall IOP & $\begin{array}{l}\text { MWR and BBSS systems have } \\
\text { been modified for serial } \\
\text { communications. AERI is not } \\
\text { planned for boundary facilities } \\
\text { until May } 1994 \text {. }\end{array}$ \\
\hline Extended facilities & Now & June & Fall IOP & $\begin{array}{l}\text { Currently operating with a } \\
\text { combination of modem and } \\
\text { diskette transfer. }\end{array}$ \\
\hline
\end{tabular}

a Abbreviations: ASAP, as soon as possible; PNL, Pacific Northwest Laboratory; TBD, to be determined.

b Date instrument will be available at the site for testing data intake software.

c Planned date for release for data intake software.

$\mathrm{d}$ Time data are required to support a specific event such as an IOP. 
TABLE 5 Observational Instruments and Systems in Place at Central and Boundary Facilities by December 31, 1993

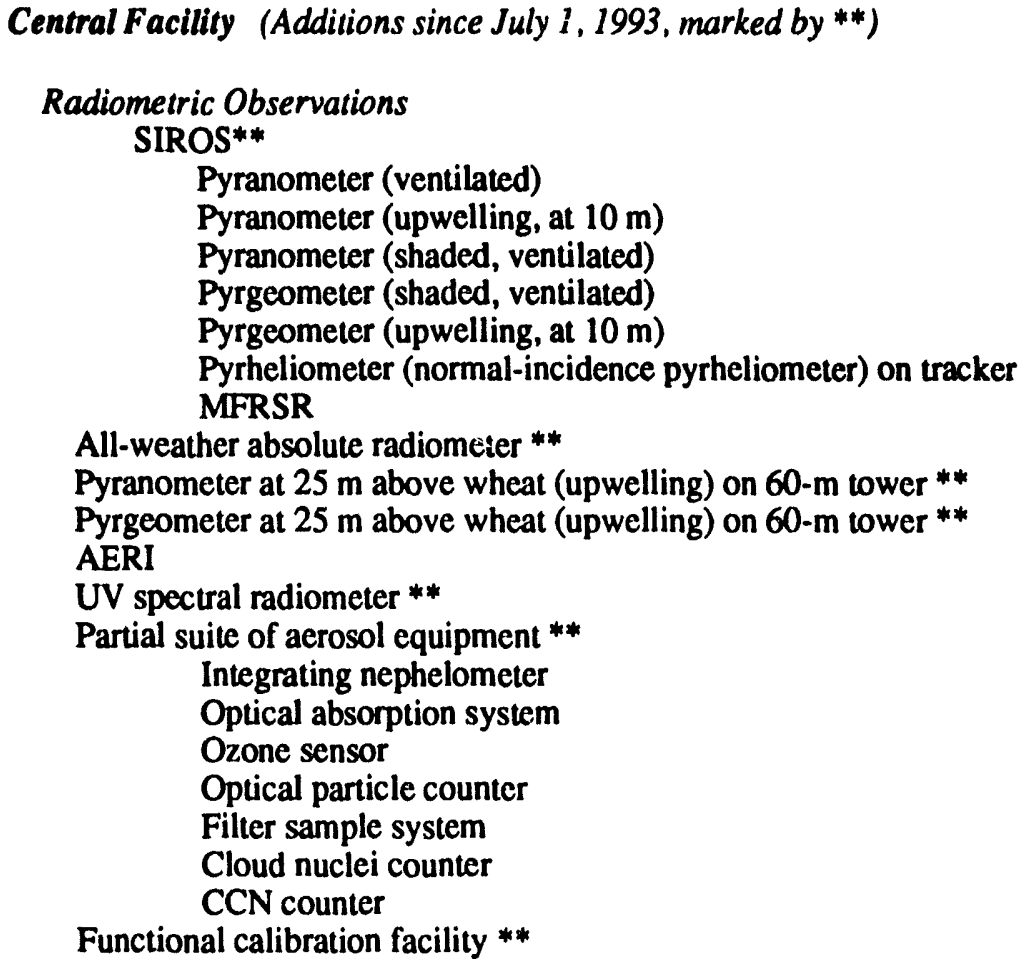

Central Facility (Additions since July 1, 1993, marked by **)

Radiometric Observations

SIROS**

Pyranometer (ventilated)

Pyranometer (upwelling, at $10 \mathrm{~m}$ )

Pyranometer (shaded, ventilated)

Pyrgeometer (shaded, ventilated)

Pyrgeometer (upwelling, at $10 \mathrm{~m}$ )

Pyrheliometer (normal-incidence pyrheliometer) on tracker MFRSR

All-weather absolute radiometer **

Pyranometer at $25 \mathrm{~m}$ above wheat (upwelling) on 60-m tower **

Pyrgeometer at $25 \mathrm{~m}$ above wheat (upwelling) on $60-\mathrm{m}$ tower **

AERI

UV spectral radiometer **

Partial suite of aerosol equipment **

Integrating nephelometer

Optical absorption system

Ozone sensor

Optical particle counter

Filter sample system

Cloud nuclei counter

CCN counter

Functional calibration facility **

Wind, Temperature, and Humidity Sounding Systems

BBSS

915-MHz profiler with RASS

50-MHz profiler with RASS**

MWR

Heimann infrared thermometer **

\section{Cloud Observations}

Interim whole-sky imager**

Belfort laser (interim) ceilometer **

Others

SMOS

EBBR

Temperature and humidity probes at $60 \mathrm{~m}$ on tower

EC system at $60 \mathrm{~m}$ on tower **

EC system near surface **

Boundary Facilities (Three facilities at Hillsboro, Kansas; Vici, Oklahoma; Morris, Oklahoma)

BBSS

MWR

AERI (probably only at Vici)

NOAA 404-MHz profiler near (may or may not have RASS) 
TABLE 6 Observational Instruments and Systems in Place at Extended Facilities by December 31, 1993a

\begin{tabular}{|c|c|c|c|c|c|}
\hline Location & SMOS & SIROS & EBBR & $\mathrm{EC}$ & MFRSR \\
\hline \multicolumn{6}{|l|}{ Kansas } \\
\hline $\begin{array}{l}\text { Ashton } \\
\text { Coldwater } \\
\text { Plevna } \\
\text { Elk City } \\
\text { Tyro } \\
\text { Towanda } \\
\text { Larned } \\
\text { LeRoy } \\
\text { Heston } \\
\text { Hillsboro }\end{array}$ & $\begin{array}{l}\mathbf{X} \\
\mathbf{X} \\
\mathbf{X} \\
\mathbf{X} \\
- \\
\mathbf{X} \\
\mathbf{X} \\
\mathbf{X} \\
\mathbf{X} \\
-\end{array}$ & $\begin{array}{l}\mathbf{X} \\
\mathbf{X} \\
\mathbf{X} \\
\mathbf{X} \\
\mathbf{X} \\
\mathbf{X} \\
\mathbf{X} \\
\mathbf{X} \\
\mathbf{X} \\
\mathbf{X}\end{array}$ & $\begin{array}{l}\mathbf{X} \\
\mathbf{X} \\
\mathbf{X} \\
\mathbf{X} \\
- \\
- \\
- \\
- \\
\\
\mathbf{X}\end{array}$ & $\begin{array}{l}- \\
- \\
- \\
- \\
\mathbf{X} \\
\mathbf{X} \\
\mathbf{X} \\
\mathbf{X} \\
\mathrm{X} \\
-\end{array}$ & $\begin{array}{l}\mathbf{X} \\
\mathbf{X} \\
\mathbf{X} \\
\mathbf{X} \\
\mathbf{X} \\
\mathbf{X} \\
\mathbf{X} \\
\mathbf{X} \\
\mathbf{X} \\
\mathbf{X}\end{array}$ \\
\hline \multicolumn{6}{|l|}{ Oklahoma } \\
\hline $\begin{array}{l}\text { Ringwood } \\
\text { Okmulgee } \\
\text { Meeker } \\
\text { Cordell } \\
\text { El Reno } \\
\text { Pawhuska } \\
\text { Vici } \\
\text { Morris } \\
\text { Ft. Cobb } \\
\text { Cyril } \\
\text { Byron }\end{array}$ & $\begin{array}{l}\mathbf{X} \\
\mathbf{X} \\
\mathbf{X} \\
- \\
- \\
- \\
- \\
- \\
\mathbf{X} \\
\mathbf{X}\end{array}$ & $\begin{array}{l}\mathbf{X} \\
\mathbf{X} \\
\mathbf{X} \\
\mathbf{X} \\
\mathbf{X} \\
\mathbf{X} \\
\mathbf{X} \\
\mathbf{X} \\
\mathbf{X} \\
\mathbf{X} \\
\mathbf{X}\end{array}$ & $\begin{array}{l}\mathbf{X} \\
- \\
\mathbf{X} \\
\mathbf{X} \\
\mathbf{X} \\
\mathbf{X} \\
- \\
\mathbf{X} \\
- \\
- \\
-\end{array}$ & $\begin{array}{l} \\
\mathbf{X} \\
- \\
- \\
- \\
\dot{x} \\
\dot{x} \\
\mathbf{X} \\
\mathbf{X} \\
\mathbf{X}\end{array}$ & $\begin{array}{l}\mathbf{X} \\
\mathbf{X} \\
\mathbf{X} \\
\mathbf{X} \\
\mathbf{X} \\
\mathbf{X} \\
\mathbf{X} \\
\mathbf{X} \\
\mathbf{X} \\
\mathbf{X} \\
\mathbf{X}\end{array}$ \\
\hline
\end{tabular}

a $\mathrm{X}$ means installed, - means no installation currently planned. Sites without SMOSes are close to either an Oklahoma Mesonet or an NWS site. Each site will have either an EBBR (over pasture) or an EC system (over cropland). All sites transfer data by modem. Two additional sites (not on this list) have been assigned a location.

remote-sensing systems. These expenses are a strong constraint on the total number of launches, making it impossible to routinely provide all of the requested launches (four to eight per day at the central and boundary facilities). Analysis of the Science Team requests suggests that a minimum number of daily launches will suffice in the interim, supplemented by seasonal IOPs that include extra launches (e.g., the seasonal SCM IOP discussed in Section 5). The IRF measurements group needs one or more daily launches at the central facility to be coincident with overpasses of polar orbiting satellites. (The actual times of passage vary from day to day.) For the DA, SCM, and HD groups, launches at the central and boundary facilities coincident with or evenly spaced between the NWS launches will be of most use. The challenge will continue to be one of balancing these needs against available funds. 
Aerosol observations and on-site calibrations of optical equipment will necessarily await modification of the aerosol and calibration trailers, installation of the instruments, and the creation of calibration procedures and data intake modules.

Routine observations at extended and boundary facilities cannot begin until the facilities are completed and data intake procedures are in place. Observations gathered during early phases of installation are written to floppy disk and hand carried to a computer for retrieval; when data intake modules have been tested, observations can be transmitted regularly through modems. Remote sensing of virtual temperature profiles at the boundary facilities will not occur during this six-month period. Installation of the proposed ARM radar profilers has been postponed because of budgetary constraints; NOAA is still testing and evaluating the RASSes under consideration for its $404-\mathrm{MHz}$ profilers.

\subsubsection{Schedule}

The establishment of a seven-day work week is necessary to support true daily BBSS launches, but the central facility will continue with a five-day work week for this six-month period, with initiation of a seven-day work week deferred until sufficient funding is available. More frequent regular BBSS launches will begin at the central facility in August 1993 with the addition of another daily launch coincident with the overpass of a polar orbiting satellite during the morning (giving a total of two launches per day). On October 1, 1993, another launch will be added at the central facility at $1200 \mathrm{UTZ} / 0700 \mathrm{CST}$ (for a total of three launches per day), as well as regular launches at the three boundary facilities at $2000 \mathrm{UTZ} / 1500 \mathrm{CST}$ to coincide with the central facility's afternoon launch. In summary, the plan for October 1-December 31 is to cunduct three BBSS launches per day (1200 UTZ/ 0700 CST to match the NWS launch; one to coincide with a satellite overpass; and 2000 UTZ/1500 CST, the continuing midafternoon launch) at the central facility and one per day at 2000 UTZ/1500 CST at each boundary facility. Plans are under discussion to increase the number of launches again during the spring of 1994, to four per day at the central facility and three per day at the boundary facilities. 


\subsection{Routine Operations by December 31, 1993}

\subsubsection{Observational Instruments and Systems}

The projected suite of installed instruments is summarized in Tables 5 and 6.

\subsubsection{Launch Schedule for BBSSes}

As indicated previously, the launch schedule for BBSSes will be three daily at the central facility, with one at $1200 \mathrm{UTZ} / 0700 \mathrm{CST}$, one coincident with a polar orbiting satellite's morning overpass, and one in the midafternoon at $2000 \mathrm{UTZ} / 1500 \mathrm{CST}$. Three boundary facilities will each launch a BBSS each day at $2000 \mathrm{UTZ} / 1500 \mathrm{CST}$.

\subsubsection{Observations and Measurements}

Table 7 summarizes both the observations that should be available at the SGP CART site and the measurements expected to be flowing from the Experiment Center by the end of December 1993.

TABLE 7 Status of CART Observations and Measurements on December 31, 1993

\begin{tabular}{|c|c|c|}
\hline Observation & Platform & Comments \\
\hline \multicolumn{3}{|l|}{ From the BBSS } \\
\hline $\begin{array}{l}\text { Sonde temperature profile } \\
\text { Sonde relative humidity profile } \\
\text { Sonde pressure profile } \\
\text { Sonde wind speed profile } \\
\text { Sonde wind direction profile }\end{array}$ & $\begin{array}{l}\text { sgpsondel } \\
\text { sgpsondel } \\
\text { sgpsonde 1 } \\
\text { sgpsonde1 } \\
\text { sgpsonde 1 }\end{array}$ & $\begin{array}{l}\text { Available } \\
\text { Available } \\
\text { Available } \\
\text { Available } \\
\text { Available }\end{array}$ \\
\hline \multicolumn{3}{|l|}{ From the MWR } \\
\hline $\begin{array}{l}\text { Column-integrated precipitable water vapor } \\
\text { Column-integrated liquid water path } \\
\text { 23.8-GHz brightness temperature } \\
\text { 31.4-GHz brightness temperature } \\
\text { Infrared }(9.5-11.5 \mu \mathrm{m}) \text { sky temperature }\end{array}$ & $\begin{array}{l}\text { sgpwvrlos 1 } \\
\text { sgpwvrlos 1 } \\
\text { sgpwvrlos 1 } \\
\text { sgpwrrlos 1 } \\
\text { sgpwvrlos 1 }\end{array}$ & $\begin{array}{l}\text { Available } \\
\text { Available } \\
\text { Available } \\
\text { Available } \\
\text { Available }\end{array}$ \\
\hline
\end{tabular}


Table 7 (Cont.)

Observation

Platform

Comments

\section{From the AERI}

Wave number $\left(520-1800 \mathrm{~cm}^{-1}\right)$

Mean radiance spectra ensemble

Standard deviation of spectra ensemble

Wave number $\left(1800-2725 \mathrm{~cm}^{-1}\right)$

Mean infrared radiance spectra ensemble

Standard deviation of spectra ensemble

Mean radiance at 675-680, 700-705, 985-990, $2295-2300,2282-2287,2510-2515 \mathrm{~cm}^{-1}$

Standard deviation of the radiance at 675-680, 700-705, 985-990, 2295-2300, 2282-2287, $2510-2515 \mathrm{~cm}^{-1}$

Brighiness temperature at 675-680, 700-705, 985-990, 2295-2300, 2282-2287. $2510-2515 \mathrm{~cm}^{-1}$

\section{From the EBBR}

Sensible heat flux to surface

Latent heat flux to surface

Net radiation flux to surface

Soil heat flux to surface

Top and bottom temperatures

Top and bottom relative humidities

Top and bottom vapor pressures

Atmospheric pressure

Soil moistures at five points

Soil temperatures at five points

Scalar and resultant wind speeds

Mean and standard deviation of wind direction

\section{From the SMOS}

Mean and standard deviation of wind speed Mean and standard deviation of wind direction Vector-averaged wind speed

Mean and standard deviation of temperature

Mean and standard deviation of relative humidity

Vapor pressure

Mean and standard deviation of barometric pressure

Snow depth

Precipitation total sgpaerilchl.al

sgpaerilchl.al

sgpaerilch1.al

sgpaerilch2.a1

sgpaerilch2.al

sgpaerilch2.al

sgpaeril summary.al

sgpaeril summary.al

sgpaerilsummary.al

Available

Available

Available

Available

Available

Available

Available

Available

Available sgp30ebbr.a1

sgp30cbbr.al

sgp30chbr.al

sgp30cbbr.a1

sgp30cbbr.a1

sgp30cbbr.al

sgp30cbbr.al

sgp30ebbr.al

sgp30cbbr.a1

sgp30ebbr.a1

sgp30cbbr.a1

sgp30ebbr.a1
Available

Available

Available

Available

Available

Available

Available

Available

Available

Available

Available

Available

sgp30smos

sgp30smos

sgp30smos

sgp30smos

sgp30smos

sgp30smos

sgp30smos

sgp30smos

sgp30smos
Available Available Available Available Available Available Available

Available Available 
TABLE 7 (Cont.)

Observation
Platform

Comments

\section{From the SIROS}

Direct beam-normal solar irradiance

Downwelling diffuse solar irradiance

Downwelling hemispherical solar irradiance

Upwelling hemispherical solar irradiance

Downwelling hemispherical irradiance

Upwelling hemispherical irradiance

Hemispherical downward solar irradiance $(415,500,610,665,862$, and $940 \mathrm{~nm})$

Hemispherical downward total solar irradiance

Diffuse hemispherical downward solar irradiance $(415,500,610,665,862$, and $940 \mathrm{~nm})$

Diffuse hemispherical downward total solar irradiance

Direct beam-normal solar irradiance $(415,500,610,665,862$, and $940 \mathrm{~nm})$

Direct beam-normal total solar irradiance

sgpsiros.al

sgpsiros.al

sgpsiros.al

sgpsiros.al

sgpsiros.al

sgpsiros.al

sgpsiros.a1

sgpsiros.al

sgpsiros.a1

sgpsiros.a1

sgpsiros.al
Available

Available

Available

Available

Available

Available

Available

Available

Available

Available

Available

From other instruments

Belfort ceilometer (cloud base height)

Spinhime ceilometer (cloud base height)

UV spectral radiometer

915-MHz profiler with RASS (wind and virtual temperature profiles)

50-MHz profiler with RASS (wind and virtual temperature profiles)

Interim whole-sky imager

\section{From the interim SIROS}

Direct beam-normal solar irradiance

Calculated downward hemispheric diffuse solar irradiance

Downwelling hemispheric solar irradiance

Solar zenith angle used in calculation

sgpsiroscalc.al sgpsiroscalc.al

sgpsiroscalc.al sgpsiroscalc.al

sgpmwrlavg.cl sgpmwrlavg.cl sgpmwrlavg.cl

sgpmwrlprof.cl
Available

Available

Available

Available

Available Available Available

Available
Average (5-min) blackbody equivalent brightness temperature

Water vapor density profile 
TABLE 7 (Cont.)

Observation
Platform

Comments

From the MFRSR

Optical depth $(415,500,610,665,862$, and

$940 \mathrm{~nm}$ )

Solar constant (same frequency as above)

Optical depth root mean square error (same frequency as above)

rsrlangley

rsrlangley

rsrlangley
NOT available

NOT available

NOT available

From various models and algorithms

Reflected solar flux at top of atmosphere (Cess algorithm)

Input for LBLRTM (line-by-line radiative transfer model)

Output from LBLRTM (infrared spectral irradiance in range $520-3020 \mathrm{~cm}^{-1}$ )

Comparison of calculated and observed irradiances

sgptoarefflx

lblrtm.input

lblrtm.output

qmelblaeri

From saiellites

Geostationary orbiting earth satellite visible brightness

Geostationary orbiting earth satellite radiance $(11.2 \mu \mathrm{m})$

AVHRR (Advanced Very High Resolution Radiometer)visible albedo ( 2 channels)

AVHRR radiance ( 3 channels)

Geostationary orbiting earth satellite temperature $(12.7,11.2,6.7 \mu \mathrm{m})$

AVHRR temperature

$\begin{array}{ll}\text { goesvis } & \text { Available } \\ \text { goesir } & \text { Available } \\ \text { avhrr } & \text { Available } \\ \text { avhr } & \text { Available } \\ \text { goesir } & \text { Available } \\ \text { avhr } & \text { Available }\end{array}$

Available

Available

Available

Available

From gridded three-dimensional (3-D) and two-dimensional (2-D) fields surrounding the SGP CART site, based on the smoothed NGM data product

Temperature (3-D)

Relative humidity (3-D)

Horizontal wind components (3-D)

Vertical (omega) wind component (3-D)

Geopotential heights (3-D)

Surface and troposperic pressure (2-D)

12-hr precipitation (2-D) ngm250.cl

ngm250.c1

ngm250.c1

ngm250.c1

ngm250.c1

ngm250.c1

ngm250.c1
Available

Available

Available

Available

Available

Available

Available

Horizontally averaged values of three fields at the SGP CART site, based on data from ngm250.cl

Surface pressure (reduced to sea level)

Tropopause pressure

Tropopause temperature ngm250derived

ngm250derived

ngm250derived
Available

Available

Available 
TABLE 7 (Cont.)

$\begin{array}{lll}\text { Observation } & \text { Platform } & \text { Comments }\end{array}$

Slab-averaged vertical profiles of three fields at the SGP CART site, based on data from ngm250

Temperature (T)

$-\left(u^{*} d T / d x+v^{*} d T / d y\right)$

Water vapor mixing ratio $(q)$

$-\left(u^{*} d g / d x+v^{*} d q / d y\right)$

Horizontal wind components ( $u$ and $v$ )

$(d u / d x+d v / d y)$

$-\left(u^{*} d u / d x+v^{*} d u / d y\right)$ and $-\left(u^{*} d v / d x+v^{*} d v / d y\right)$

Geopotential height (Z)

$\mathrm{dZ} / \mathrm{dx}$ and $\mathrm{dZ} / \mathrm{dy}$

$\mathrm{d} 2 \mathrm{~T} / \mathrm{d} \times 2, \mathrm{~d} 2 \mathrm{~T} / \mathrm{dy} 2$

$d 2 q / d \times 2, d 2 q / d y 2$

$d 2 u / d \times 2, d 2 u / d y 2$

$\mathrm{d} 2 \mathrm{v} / \mathrm{d} \times 2, \mathrm{~d} 2 \mathrm{v} / \mathrm{dy} 2$

Other external data

Gridded meteorological fields from Forecast Systems Laboratory (FSL) MAPS model (8/day): height, temperature, relative humidity, horizontal wind component, every $25 \mathrm{kPa}$ from surface to $100 \mathrm{kPa}$

Gridded meteorological ficlds from NMC Eta model (4/day): height, temperature, relative humidity, horizontal wind component, every $50 \mathrm{kPa}$ from surface to $100 \mathrm{kPa}$

Profile of wind components from NOAA wind profiler $(404 \mathrm{MHz}$ ) demonstration network

Products from short-wave geostationary orbiting earth satellite data provided by Gautier:

Shortwave surface irradiance

Shortwave directional reflectance ("albedo")

Shortwave cloud transmittance

NWS surface hourly observations

NWS upper air observations

Kansas network of surface hourly observations:

air temperature, relative humidity, wind

direction, wind speed, total solar radiance, total

rainfall, and $10-\mathrm{cm}$ soil temperature

Oklahoma Mesonet surface observations ngm250derived

ngm250derived

ngm250derived

ngm250derived

ngm250derived

ngm250derived

ngm250derived

ngm250derived

ngm250derived

ngm250derived

ngm250derived

ngm250derived

ngm250derived
Available

Available

Available

Available

Available

Available

Available

Available

Available

Available

Available

Available

Available 


\section{SPECIAL OPERATIONS}

The base of the ARM CART program is a suite of continuous observations, but a number of critical observations are either too expensive to be produced continuously at the desired frequency or require instrumentation that cannot be continuously deployed. However, on some occasions questions concerning data accuracy or representativeness (for either established instruments or prototypes) can only answered be with periods of more frequent observations. Acquiring these observations will require special efforts and arrangements by the SGP site staff; they are categorized as special operations (commonly referred to as IOPs, because they frequently include activities beyond the routine observations). The IOPs can be in support of the needs of the Science Team, QMEs, IDPs, campaigns, and even field tests of non-CART instruments. Table 8 lists IOPs that have occurred, are occurring, or are in the design stage.

The initial design of all special operations will be in the hands of the EST. Prototype procedures to facilitate the design, review, and implementation process are outlined in a planning document for IOPs by Dickerson and Cederwall. Similar documents are being prepared by the Campaign Team leader to facilitate interagency collaborations and by the Operations Team leader to facilitate guest instruments. The SST will assist the EST in the generation of plans for special operations; will include the approved QMEs, IOPs, and campaigns in the Site Scientific Mission Plan; and will assist in the execution of special operations.

The following descriptions of special operations are sketchy in comparison to the previous section on routine operations, as should be expected at this stage in the development of the SGP CART site and the ARM Program as a whole. Once the principal SGP site development is complete, the focus will naturally shift to more in-depth work both examining and completing gaps in the data stream, and this portion of the Site Scientific Mission Plan will expand accordingly. The information presented here, which summarizes the knowledge currently in hand on all special operations, should be sufficient to generate interprogram attention and discussion.

\subsection{Quality Measurement Experiments}

As part of the data quality assurance effort, our focus needs to go far beyond the simple calibration of instruments, to intercomparison of data streams and to evaluations of our ability to capture an accurate representation of the state of the atmosphere. The QMEs are experiments that address these problems and are designed and managed in a manner analogous to the 
TABLE 8 Intensive Observation Periods

\begin{tabular}{|c|c|c|c|c|c|}
\hline Date & Name & $\begin{array}{l}\text { Science Team } \\
\text { Member }^{\mathrm{a}}\end{array}$ & $\begin{array}{l}\text { EST } \\
\text { Contact }\end{array}$ & Description & Status \\
\hline $7 / 92-12 / 92$ & $\begin{array}{l}\text { Field Test of NCAR } \\
\text { Flux Profiler }\end{array}$ & D. Parsons (NCAR) & R. Cederwall & $\begin{array}{l}\text { Enhanced soundings at the central } \\
\text { facility and profiler site were made } \\
11 / 10-11 / 19 ; \text { boundary layer flights } \\
\text { were also conducted on a few days. }\end{array}$ & $\begin{array}{l}\text { Completed; data available } \\
\text { summer } 1993 .\end{array}$ \\
\hline \multirow[t]{3}{*}{$1 / 93-6 / 93$} & AERI Field Test & H. Revercomb (UW) & J. Liljegren & $\begin{array}{l}\text { Enhanced soundings at the central } \\
\text { facility are requested during the field } \\
\text { acceptance test of the AERI } \\
\text { instrument. }\end{array}$ & Completed 4/29/93. \\
\hline & $\begin{array}{l}\text { Using the Global } \\
\text { Positioning System } \\
\text { (GPS) for the } \\
\text { Measurement of } \\
\text { Atmospheric Water } \\
\text { Vapor }\end{array}$ & $\begin{array}{l}\text { Collaborative } \\
\text { (UNAVCO and NCSU) }\end{array}$ & J. Liljegren & $\begin{array}{l}\text { The purpose is to test the } \\
\text { investigators' technique for interfering } \\
\text { total precipitable water vapor in the } \\
\text { atmosphere column by using GPS } \\
\text { signals; time frame is May } 1993 \text {. }\end{array}$ & $\begin{array}{l}\text { Completed 6/8/93; reduced } \\
\text { data will be sent to ARM } \\
\text { in fall 1993. ARM MWR } \\
\text { and BBSS data delivered } \\
\text { 7/2/93; SMOS data } \\
\text { delivery awaiting mentor } \\
\text { approval. }\end{array}$ \\
\hline & $\begin{array}{l}\text { Warm Season Data } \\
\text { Assimilation and } \\
\text { Integrated Sounding } \\
\text { System (ISS) Test }\end{array}$ & D. Parsons (NCAR) & R. Cederwall & $\begin{array}{l}\text { This is an enhanced sampling (in time } \\
\text { and space) of the SGP domain for a } \\
\text { 10-day period with profilers and } \\
\text { sondes. The primary goals of the IOP } \\
\text { are (1) to study the performance of } \\
\text { four-dimensional data assimilation } \\
\text { (FDDA) under thermodynamic } \\
\text { conditions typical of the continental } \\
\text { warm season and (2) to evaluate the } \\
\text { estimates of divergence and vorticity } \\
\text { from the prototype NCAR ISS with } \\
\text { interferometric techniques, the triangle } \\
\text { of three 915-MHz profilers, and the } \\
\text { results of FDDA. }\end{array}$ & $\begin{array}{l}\text { Completed; ran for } 10 \\
\text { days }(6 / 16-6 / 25) ; \text { data } \\
\text { available in late summer } \\
\text { or early fall. }\end{array}$ \\
\hline
\end{tabular}


TABLE 8 (Cont.)

\begin{tabular}{|c|c|c|c|c|c|}
\hline Date & Name & $\begin{array}{c}\text { Science Team } \\
\text { Member }^{\mathbf{a}}\end{array}$ & $\begin{array}{c}\text { EST } \\
\text { Contact }\end{array}$ & Description & Status \\
\hline \multirow[t]{3}{*}{$1 / 94-6 / 94$} & $\begin{array}{l}\text { Simultaneous Ground- } \\
\text { Based, Airbome, and } \\
\text { Satellite-Bome } \\
\text { Microwave Radiometric } \\
\text { and In Situ Observations } \\
\text { of Cloud Optical } \\
\text { Properties and Surface } \\
\text { Emissivities }\end{array}$ & $\begin{array}{l}\text { W. Wiscombe (NASA- } \\
\text { GSFC); E. Westwater } \\
\text { (NOAA-WPL) }\end{array}$ & J. Liljegren & $\begin{array}{l}\text { Observations of cloud optical } \\
\text { properties will be obtained over the } \\
\text { CART site simultaneously from } \\
\text { ground-based, in situ, and satellite- } \\
\text { based sensors; spatial variability of } \\
\text { surface emmissivities will be assessed } \\
\text { in order to attempt retrieval of total } \\
\text { precipitable water and cloud liquid } \\
\text { water from the special sensor } \\
\text { microwave imager. }\end{array}$ & $\begin{array}{l}\text { Proposal distributed (to } \\
\text { IRF); initial planning } \\
\text { discussions between } \\
\text { Wiscombe and L. Fedor at } \\
\text { NOAA; looking at } \\
\text { January } 1994 .\end{array}$ \\
\hline & Seasonal SCM IOP & D. Randall (CSU) & M. Bradley & $\begin{array}{l}\text { Seasonal IOP with enhanced frequency } \\
\text { of observations, particularly vertical } \\
\text { soundings of temperature, water } \\
\text { vapor, and winds at central facility and } \\
\text { boundary facilities for periods of } 2-3 \\
\text { weeks; the required sounding frequency } \\
\text { is } 6-8 / \text { day. The data are required for } \\
\text { quantifying boundary forcing and } \\
\text { column response. Enhanced radiative } \\
\text { transfer measurements will likely be } \\
\text { required. }\end{array}$ & $\begin{array}{l}\text { Discussion in progress; } \\
\text { proposal in preparation; } \\
\text { first IOP in either fall } \\
1993 \text { or winter } 1994 \text {, } \\
\text { depending on } \\
\text { observational ability. }\end{array}$ \\
\hline & $\begin{array}{l}\text { Feasibility Tests of } \\
\text { ARM Unmanned } \\
\text { Aerospace Vehicle } \\
\text { (UAV) }\end{array}$ & $\begin{array}{l}\text { J. Vitko (SNL); } \\
\text { G. Stokes (PNL) }\end{array}$ & J. Liljegren & $\begin{array}{l}\text { Measurements of clear-sky flux } \\
\text { profiles acquired by an UAV and } \\
\text { surface support data, to be used to } \\
\text { understand clear-sky heating rates and } \\
\text { the ability of models to reproduce the } \\
\text { observations. }\end{array}$ & $\begin{array}{l}\text { Planned for February } \\
1994 .\end{array}$ \\
\hline
\end{tabular}


TABLE 8 (Cont.)

\begin{tabular}{|c|c|c|c|c|c|}
\hline Date & Name & $\begin{array}{c}\text { Science Team } \\
\text { Member }^{\mathrm{a}}\end{array}$ & $\begin{array}{c}\text { EST } \\
\text { Contact }\end{array}$ & Description & Status \\
\hline $1 / 94-6 / 94$ & $\begin{array}{l}\text { Cloud Observation IDP } \\
\text { Field Evaluation }\end{array}$ & $\begin{array}{l}\text { R. McIntosh (UM); } \\
\text { B. Kropfli (NOAA); T. } \\
\text { Ackerman (PSU); } \\
\text { K. Sassen (UU); } \\
\text { A. Heymsfield } \\
\text { (NCAR); and others }\end{array}$ & $\begin{array}{l}\text { M. Bradley; } \\
\text { J. Griffin (IDP } \\
\text { contact) }\end{array}$ & $\begin{array}{l}\text { The primary purpose is the field } \\
\text { evaluation and calibration for several } \\
\text { remote-sensing, cloud-observing } \\
\text { instruments (some of which are from } \\
\text { the IDP project). In situ cloud } \\
\text { observations are critical to the success } \\
\text { of this IOP. Enhanced soundings will } \\
\text { also be required at the central facility. }\end{array}$ & $\begin{array}{l}\text { Discussion in progress; } \\
\text { proposal in preparation; } \\
\text { planned for spring 1994; } \\
\text { preliminary planning } \\
\text { meeting held in } \\
\text { Breckenridge, Colorado, } \\
\text { on } 6 / 14 / 93 \text {. }\end{array}$ \\
\hline
\end{tabular}

a Affiliations: CSU, Colorado State University; GSFC, Goddard Space Flight Center, NASA, National Aeronautics and Space Administration; NCAR, National Center for Atmospheric Research; NCSU, North Carolina State University; NOAA, National Oceanic and Atmospheric Administration;

PNL, Pacific Northwest Laboratory; PSU, Pennsylvania State University; SNLL, Sandia National Laboratory; UM, University of Massachussetts;

UNAVCO, University NAVSTAR Consortium; UU, University of Utah; UW, University of Wisconsin; WPL, Wave Propagation Laboratory. 
experimental designs of the Science Team members. While QMEs can be proposed by anyone within the ARM Program, they constitute a special joint responsibility for the SST, the EST, and the Experiment Center. The following is an example:

QME Name:

Science Team Member: (STM Contact)

EST Contact:

Brief Description:

Status:

Obvious QMEs that are either in preparation or under consideration include the following:

- Comparison of broadband radiative surface fluxes, both between instruments measuring the same quantity and calculated from combinations of observations. This effort is currently in draft form and will be developed further and executed when the new SIROS is installed at the central facility (in preparation).

- Comparison of thermodynamic profiles derived from the BBSS and the RASS profilers, with near-surface values from the SMOS and from the $60-\mathrm{m}$ tower instruments (under consideration; awaiting installation of the $50-\mathrm{MHz}$ profiler). 
- Comparison of wind profiles derived from the BBSS and the profilers (under consideration; awaiting installation of the $50 \mathrm{MHz}$ profiler).

- Comparison of the fluxes derived from the EBBR and EC systems (under consideration, awaiting installation of the EC system at the central facility).

- Comparison of cloud observations from the whole-sky imager, the ceilometer, and any cloud radars deployed at the central facility for IOPs (under consideration; awaiting installations and IOPs including cloud radars).

The results of these and other QMEs will have both short- and long-term effects on the ARM data stream and on site management, including advisories to the Science Team concerning data quality, modifications in data acquisition strategies, and reassessments of measurement algorithms. The most important and unique of the instrument comparisons will be distributed as internal ARM reports and submitter for publication in appropriate journals.

\subsection{Intensive Observation Periods to Support Instrument Development Programs}

The SGP CART site is an ideal location for rigorous field tests of new observational systems and has been designed to support these activities with a minimum of disruption to the continuous observations. Six of the IOPs in Table 8 were designed to support various instrument development activities. The field tests of the NCAR flux profiler (July-December 1992 and January-June 1993) are continuing efforts in the development of an instrument that will remotely and continuously measure near-surface momentum and virtual temperature fluxes. The AERI (January-June 1993) should be capable of routine detection of infrared radiances with high spectral resolution and accuracy and will be essential to experiments on the effects of greenhouse gases, clouds, and fine particles on atmospheric transmission, absorption, and emission. AERIs are also scheduled for later deployment at the SGP boundary facilities, where they will be used to infer vertical profiles of temperature and humidity below the cloud base. The global positioning system is an example of use of a problem (noise in the data stream of the system) in an attempt to produce a continuous, low-cost measurement (total water vapor in the intervening atmosphere, and possibly profiles of water vapor) that would be of value to the ARM Program. The SGP CART site will also be a logistically friendly base for early tests of the ARM unmanned aircraft (July-December 1993), a platform that figures prominently in plans for future oceanic CART sites. The Cloud Observation IDP Field Evaluation (January-June 1994) will be a critical step 
forward in our ability to remotely and continuously observe both cloud distribution and microstructure, which are currently unfilled SGP observational needs.

\subsection{Intensive Observation Periods to Supplement Continuous Observations}

Three of the IOPs listed in Table 8 are primarily for the purpose of testing instrument systems intended for possible ARM deployment, but they will also produce supplemental data of use to the Science Team at large (the Field Test of NCAR Flux Profiler, the Warm Season Data Assimilation and Integrated Sounding System Test, and the Cloud Observation IDP Field Evaluation). Two other IOPs listed in Table 8 will specifically address other unfilled observational needs of the SCM and DA groups: the Wiscombe-Westwater cloud observations and the Seasonal SCM IOP. The only critical dependency in site development for these IOPs is the necessary completion of the first three boundary facilities before a fall SCM IOP can be conducted.

\subsection{Campaign Planning}

Table 9 summarizes potential campaigns and cooperative projects that have been called to our attention. Plans for these activities are in various stages of development, and the topics are briefly listed here to generate further discussion. Inclusion in this list does not imply any endorsement of these activities by the ARM Program, with the exception of the Global Energy and Water Cycle Experiment (GEWEX) GVaP (GEWEX Water Vapor Project) as the Department of Energy's contribution to GEWEX. 
TABLE 9 Collaborative Campaigns and Activities under Discus sion

Title

Proponent/Contact ${ }^{\mathrm{a}}$

Projected Date

Flux Divergence

J. Vitko

Fall 1993

Ultraviolet B Intercomparison
A. Thompson
Fall 1993
(NIST, DOA)
H. Melfi
?

GEWEX GVaP

Water Vapor Profile Intercomparison

GEWEX ISLSCP/GCIPb

P. Sellers

Integrated GEWEX System Test (GIST)

Land Surface Studies

GEWEX Cloud System Study (GCSS)

M. Moncrieff

Spring 1995

Cooperative Multiscale Experiment

W. Cotton (CSU)

W. Blumen (CU)

Spring 1994

W. Pennell

?

Boundary Layer Facility

E. Rasmussen (NSSL)

?

Spring, Summer 1995

?

$?$

Tornado Field Experiment

(VORTEX)

a Affiliations: CSU, Colorado State University; CU, Colorado University; DOA, Department of Agriculture; NIST, National Institute of Standards and Technology; NSSL, National Severe Storms Laboratory.

b ISLSCP/GCIP, International Satellite Land-Surface Climatology Project/GEWEX Continental-Scale International Project. 